Network Working Group

Request for Comments: 2235

FYI : 32

Category: Informational
R. Zakon

MITRE

November 1997

\title{
Hobbes' Internet Timeline
}

Status of this Memo

This memo provides information for the Internet community. It does not specify an Internet standard of any kind. Distribution of this memo is unlimited.

Copyright Notice

Copyright (C) Robert H. Zakon and The Internet Society (1997). All Rights Reserved.

1. Introduction

This document presents a history of the Internet in timeline fashion, highlighting some of the key events and technologies which helped shape the Internet as we know it today. A growth summary of the Internet and some associated technologies is also included.

2. Hobbes' Internet Timeline

Excerpted from the author's copyrighted work of the same name. The most current version of Hobbes' Internet Timeline is available at http://info.isoc.org/guest/zakon/Internet/History/HIT.html

$1950 \mathrm{~s}$

1957

USSR launches Sputnik, first artificial earth satellite. In response, US forms the Advanced Research Projects Agency (ARPA) within the Department of Defense (DOD) to establish US lead in science and technology applicable to the military (:amk:)

$1960 \mathrm{~s}$

1962

Paul Baran, RAND: "On Distributed Communications Networks"

- Packet-switching (PS) networks; no single outage point 
ARPA sponsors study on "cooperative network of time-sharing computers"

- TX-2 at MIT Lincoln Lab and Q-32 at System Development Corporation (Santa Monica, CA) are directly linked (without packet switches)

1967

ACM Symposium on Operating Principles

- Plan presented for a packet-switching network

- First design paper on ARPANET published by Lawrence G. Roberts

National Physical Laboratory (NPL) in Middlesex, England develops NPL Data Network under D. W. Davies

1968

PS-network presented to the Advanced Research Projects Agency (ARPA)

1969

ARPANET commissioned by DoD for research into networking

- First node at UCLA, Network Measurements Center

[SDS SIGMA 7, SEX] and soon after at:

- Stanford Research Institute (SRI), NIC [SDS940/Genie]

- UCSB, Culler-Fried Interactive Mathematics [IBM 360/75, OS/MVT]

- Univ of Utah, Graphics [DEC PDP-10, Tenex]

- use of Information Message Processors (IMP) [Honeywell 516 mini computer with $12 \mathrm{~K}$ of memory developed by Bolt Beranek and Newman, Inc. (BBN)

First Request for Comment (RFC): "Host Software" by Steve Crocker

Univ of Michigan, Michigan State and Wayne State Univ establish

x.25-based Merit network for students, faculty, alumni (:sw1:)

$1970 \mathrm{~s}$

Store-and-forward networks

- Used electronic mail technology and extended it to conferencing 
ALOHAnet developed by Norman Abrahamson, Univ of Hawaii (:sk2:)

- connected to the ARPANET in 1972

ARPANET hosts start using Network Control Protocol (NCP).

1971

15 nodes (23 hosts): UCLA, SRI, UCSB, Univ of Utah, BBN, MIT, RAND, SDC, Harvard, Lincoln Lab, Stanford, UIU(C), CWRU, CMU, NASA/Ames

Ray Tomlinson of BBN invents email program to send messages across a distributed network. The original program was derived from two others: an intra-machine email program (SNDMSG) and an experimental file transfer program (CPYNET) (:amk:irh:)

1972

International Conference on Computer Communications with demonstration of ARPANET between 40 machines and the Terminal Interface Processor (TIP) organized by Bob Kahn.

InterNetworking Working Group (INWG) created to address need for establishing agreed upon protocols. Chairman: Vinton Cerf.

Telnet specification (RFC 318)

1973

First international connections to the ARPANET: University College of London (England) and Royal Radar Establishment (Norway)

Bob Metcalfe's Harvard PhD Thesis outlines idea for Ethernet $($ : amk: )

Bob Kahn poses Internet problem, starts internetting research program at ARPA. Vinton Cerf sketches gateway architecture in March on back of envelope in hotel lobby in San Francisco (:vgc:)

Cerf and Kahn present basic Internet ideas at INWG in september at Univ of Sussex, Brighton, UK (:vgc:)

File Transfer specification (RFC 454)

1974

Vint Cerf and Bob Kahn publish "A Protocol for Packet Network Intercommunication" which specified in detail the design of a Transmission Control Program (TCP). [IEEE Trans Comm] (:amk:)

BBN opens Telenet, the first public packet data service (a commercial version of ARPANET) (:sk2:) 
1975

Operational management of Internet transferred to DCA (now DISA)

"Jargon File", by Raphael Finkel at SAIL, first released (:esr:)

Shockwave Rider written by John Brunner (:pds:)

1976

Elizabeth II, Queen of the United Kingdom sends out an e-mail

(various Net folks have e-mailed dates ranging from 1971 to 1978;

1976 was the most submitted and the only found in print)

UUCP (Unix-to-Unix CoPy) developed at AT\&T Bell Labs and

distributed with UNIX one year later.

1977

THEORYNET created by Larry Landweber at Univ of Wisconsin providing electronic mail to over 100 researchers in computer science (using a locally developed email system and TELENET for access to server).

Mail specification (RFC 733)

Tymshare launches Tymnet

First demonstration of ARPANET/Packet Radio Net/SATNET operation of Internet protocols with BBN-supplied gateways in July (:vgc:)

1979

Meeting between Univ of Wisconsin, DARPA, NSF, and computer scientists from many universities to establish a Computer Science Department research computer network (organized by Larry Landweber)

USENET established using UUCP between Duke and UNC by Tom Truscott, Jim Ellis, and Steve Bellovin. All original groups were under net.* hierarchy.

First MUD, MUD1, by Richard Bartle and Roy Trubshaw at U of Essex

ARPA establishes the Internet Configuration Control Board (ICCB)

Packet Radio Network (PRNET) experiment starts with DARPA funding. Most communications take place between mobile vans. ARPANET connection via SRI. 
1981

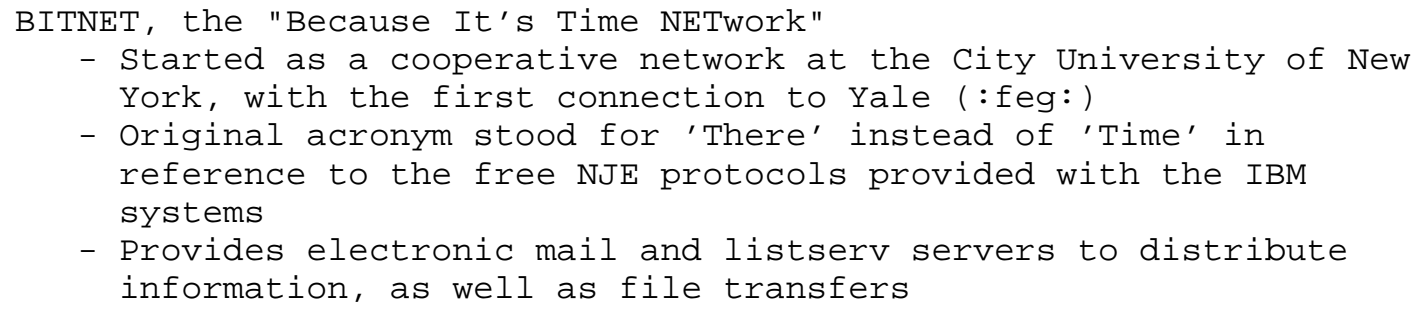


ARPANET split into ARPANET and MILNET; the latter became integrated with the Defense Data Network created the previous year.

Desktop workstations come into being, many with Berkeley UNIX which includes IP networking software.

Networking needs switch from having a single, large time sharing computer connected to the Internet at each site, to instead connecting entire local networks.

Internet Activities Board (IAB) established, replacing ICCB

Berkeley releases 4.2BSD incorporating TCP/IP (:mpc:)

EARN (European Academic and Research Network) established. Very similar to the way BITNET works with a gateway funded by IBM.

FidoNet developed by Tom Jennings.

1984

Domain Name System (DNS) introduced.

Number of hosts breaks 1,000

JUNET (Japan Unix Network) established using UUCP.

JANET (Joint Academic Network) established in the UK using the Coloured Book protocols; previously SERCnet.

Moderated newsgroups introduced on USENET (mod.*)

Neuromancer written by William Gibson

1985

Whole Earth 'Lectronic Link (WELL) started

Information Sciences Institute (ISI) at USC is given responsibility for DNS root management by DCA, and SRI for DNS NIC registrations

Symbolics.com is assigned on 15 March to become the first registered domain. Other firsts: cmu.edu, purdue.edu, rice.edu, ucla.edu (April); css.gov (June); mitre.org, .uk (July)

100 years to the day of the last spike being driven on the crossCanada railroad, the last Canadian university is connected to BITNET in a one year effort to have coast-to-coast connectivity. (:kf1:) 
1986

NSFNET created (backbone speed of 56Kbps)

- NSF establishes 5 super-computing centers to provide high-computing power for all (JVNCQPrinceton, PSCQPittsburgh, SDSC@UCSD, NCSA@UIUC, Theory Center@Cornell).

- This allows an explosion of connections, especially from universities.

NSF-funded SDSCNET, JVNCNET, SURANET, and NYSERNET operational ( : sw1:)

Internet Engineering Task Force (IETF) and Internet Research Task Force (IRTF) comes into existence under the IAB. First IETF meeting held in January at Linkabit in San Diego

The first Freenet (Cleveland) comes on-line 16 July under the auspices of the Society for Public Access Computing (SoPAC). Later Freenet program management assumed by the National Public Telecomputing Network (NPTN) in 1989 (:sk2, rab:)

Network News Transfer Protocol (NNTP) designed to enhance Usenet news performance over TCP/IP.

Mail Exchanger (MX) records developed by Craig Partridge allow non-IP network hosts to have domain addresses.

The great USENET name change; moderated newsgroups changed in 1987.

BARRNET (Bay Area Regional Research Network) established using high speed links. Operational in 1987.

1987

NSF signs a cooperative agreement to manage the NSFNET backbone with Merit Network, Inc. (IBM and MCI involvement was through an agreement with Merit). Merit, IBM, and MCI later founded ANS.

UUNET is founded with Usenix funds to provide commercial UUCP and Usenet access. Originally an experiment by Rick Adams and Mike o' Dell

Email link established between Germany and China using CSNET protocols, with the first message from China sent on 20 september. $(:$ wz1:)

1000th RFC: "Request For Comments reference guide"

Number of hosts breaks 10,000 
Number of BITNET hosts breaks 1,000

1988

2 November - Internet worm burrows through the Net, affecting

$\sim 6,000$ of the 60,000 hosts on the Internet (:ph1:)

CERT (Computer Emergency Response Team) formed by DARPA in response to the needs exhibited during the Morris worm incident. The worm is the only advisory issued this year.

DoD chooses to adopt OSI and sees use of TCP/IP as an interim. US Government OSI Profile (GOSIP) defines the set of protocols to be supported by Government purchased products (:gck:)

Los Nettos network created with no federal funding, instead supported by regional members (founding: Caltech, TIS, UCLA, USC, ISI).

NSFNET backbone upgraded to T1 (1.544Mbps)

CERFnet (California Education and Research Federation network) founded by Susan Estrada.

Internet Relay Chat (IRC) developed by Jarkko Oikarinen (:zby:)

First Canadian regionals join NSFNET: ONet via Cornell, RISQ via Princeton, BCnet via Univ of Washington (:ec1:)

FidoNet gets connected to the Net, enabling the exchange of e-mail and news (:tp1:)

Countries connecting to NSFNET: Canada (CA), Denmark (DK), Finland $(F I)$, France (FR), Iceland (IS), Norway (NO), Sweden (SE)

1989

Number of hosts breaks 100,000

RIPE (Reseaux IP Europeens) formed (by European service providers) to ensure the necessary administrative and technical coordination to allow the operation of the pan-European IP Network. (:glg:)

First relays between a commercial electronic mail carrier and the Internet: MCI Mail through the Corporation for the National Research Initiative (CNRI), and Compuserve through Ohio State Univ $(: j g 1, \operatorname{ph} 1:)$

Corporation for Research and Education Networking (CREN) is formed by merging CSNET into BITNET 
AARNET - Australian Academic Research Network - set up by AVCC and CSIRO; introduced into service the following year (:gmc:)

Cuckoo's Egg written by Clifford Stoll tells the real-life tale of a German cracker group who infiltrated numerous US facilities

CERT advisories: 7

Countries connecting to NSFNET: Australia (AU), Germany (DE), Israel (IL), Italy (IT), Japan (JP), Mexico (MX), Netherlands (NL), New Zealand (NZ), Puerto Rico (PR), United Kingdom (UK)

$1990 s$

1990

ARPANET ceases to exist

Electronic Frontier Foundation (EFF) is founded by Mitch Kapor

Archie released by Peter Deutsch, Alan Emtage, and Bill Heelan at McGill

Hytelnet released by Peter Scott (Univ of Saskatchewan)

The World comes on-line (world.std.com), becoming the first commercial provider of Internet dial-up access

ISO Development Environment (ISODE) developed to provide an approach for OSI migration for the DOD. ISODE software allows OSI application to operate over TCP/IP (:gck:)

$\mathrm{CA}^{\star}$ net formed by 10 regional networks as national Canadian backbone with direct connection to NSFNET (:ec1:)

The first remotely operated machine to be hooked up to the Internet, the Internet Toaster, (controlled via SNMP) makes its debut at Interop.

CERT advisories: 12, reports: 130

Countries connecting to NSFNET: Argentina (AR), Austria (AT), Belgium (BE), Brazil (BR), Chile (CL), Greece (GR), India (IN), Ireland (IE), Korea (KR), Spain (ES), Switzerland (CH) 
1991

Commercial Internet exchange (CIX) Association, Inc. formed by General Atomics (CERFnet), Performance systems International, Inc. (PSInet), and UUNET Technologies, Inc. (AlterNet), after NSF lifts restrictions on the commercial use of the Net (:glg:)

Wide Area Information Servers (WAIS), invented by Brewster Kahle, released by Thinking Machines Corporation

Gopher released by Paul Lindner and Mark P. McCahill from the Univ of Minnessota

World-Wide Web (WWW) released by CERN; Tim Berners-Lee developer $(: \mathrm{pb} 1:)$

PGP (Pretty Good Privacy) released by Philip Zimmerman (:ad1:)

US High Performance Computing Act (Gore 1) establishes the National Research and Education Network (NREN)

NSENET backbone upgraded to T3 (44.736Mbps)

NSFNET traffic passes 1 trillion bytes/month and 10 billion packets/month

Defense Data Network NIC contract awarded by DISA to Government Systems Inc. who takes over from SRI in May

Start of JANET IP Service (JIPS) which signalled the changeover from Coloured Book software to TCP/IP within the UK academic network. IP was initially 'tunnelled' within X.25. (:gst:)

CERT advisories: 23

Countries connecting to NSFNET: Croatia (HR), Czech Repulic (CZ), Hong Kong (HK), Hungary (HU), Poland (PL), Portugal (PT), Singapore (SG), South Africa (ZA), Taiwan (TW), Tunisia (TN)

1992

Internet Society (ISOC) is chartered

Number of hosts breaks 1,000,000

First MBONE audio multicast (March) and video multicast (November)

RIPE Network Coordination Center (NCC) created in April to provide address registration and coordination services to the European Internet community $(: \mathrm{dk} 1:)$ 
IAB reconstituted as the Internet Architecture Board and becomes part of the Internet society

Veronica, a gopherspace search tool, is released by Univ of Nevada

World Bank comes on-line

Japan's first ISP, Internet Initiative Japan (IIJ), is formed by Koichi Suzuki

The term "Surfing the Internet" is coined by Jean Armour Polly $(:$ jap: $)$

Internet Hunt started by Rick Gates

CERT advisories: 21 , reports: 800

Countries connecting to NSFNET: Antarctica (AQ), Cameroon (CM), Cyprus (CY), Ecuador (EC), Estonia (EE), Kuwait (KW), Latvia (LV), Luxembourg (LU), Malaysia (MY), Slovakia (SK), Slovenia (SI), Thailand $(\mathrm{TH})$, Venezuela (VE)

1993

InterNIC created by NSF to provide specific Internet services: $(: \operatorname{sc} 1:)$

- directory and database services (AT\&T)

- registration services (Network Solutions Inc.)

- information services (General Atomics/CERFnet)

US White House comes on-line (http://www.whitehouse.gov/):

- President Bill Clinton: president@whitehouse.gov

- Vice-President Al Gore: Vice-president@whitehouse.gov

Worms of a new kind find their way around the Net - WWW Worms (W4), joined by Spiders, Wanderers, Crawlers, and Snakes ...

Internet Talk Radio begins broadcasting (:sk2:)

United Nations (UN) comes on-line (:vgc:)

US National Information Infrastructure Act

Businesses and media really take notice of the Internet

Mosaic takes the Internet by storm; WWW proliferates at a 341,634\% annual growth rate of service traffic. Gopher's growth is $997 \%$.

CERT advisories: 18, reports: 1300 


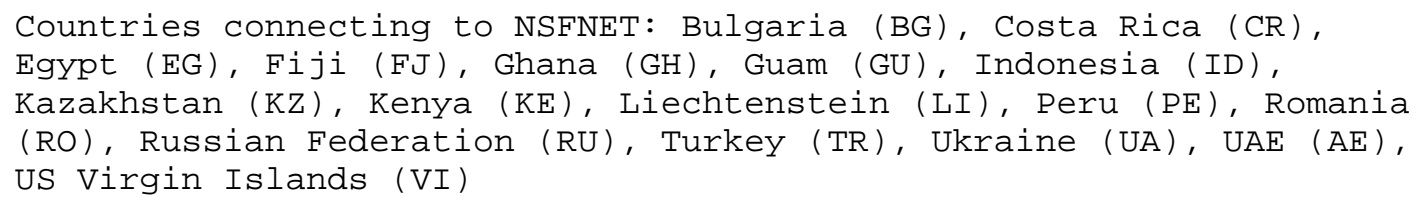




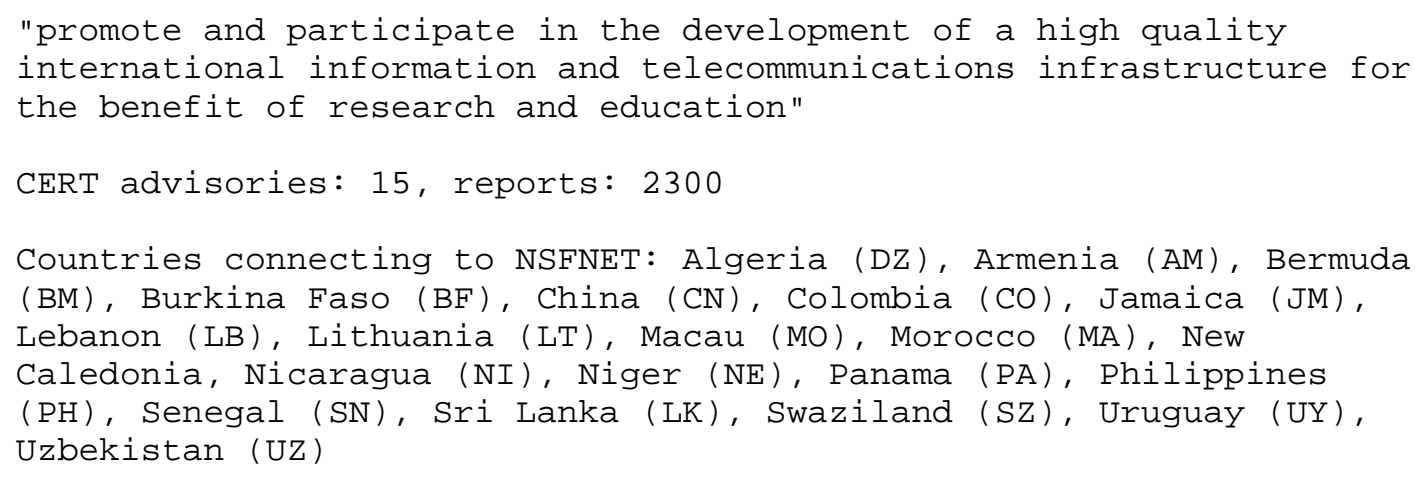


Registration of domain names is no longer free. Beginning 14 September, a $\$ 50$ annual fee has been imposed, which up until now was subsidized by NSF. NSF continues to pay for .edu registration, and on an interim basis for .gov

The Vatican comes on-line

The Canadian Government comes on-line

The first official Internet wiretap was successful in helping the Secret Service and Drug Enforcement Agency (DEA) aprehend three individuals who were illegally manufacturing and selling cell phone cloning equipment and electronic devices

Operation Home Front connects, for the first time, soldiers in the field with their families back home via the Internet.

Richard White becomes the first person to be declared a munition, under the USA's arms export control laws, because of an RSA file security encryption program emblazoned on his arm (:wired496:)

CERT advisories: 18 , reports: 2412

Country domains registered: Ethiopia (ET), Cote d'Ivoire (CI), Cook Islands (CK) Cayman Islands (KY), Anguilla (AI), Gibraltar (GI), Vatican (VA), Kiribati (KI), Kyrgyzstan (KG), Madagascar (MG), Mauritius (MU), Micronesia (FM), Monaco (MC), Mongolia (MN), Nepal (NP), Nigeria (NG), Western Samoa (WS), San Marino (SM), Tanzania (TZ), Tonga (TO), Uganda (UG), Vanuatu (VU)

Technologies of the Year: WWW, Search engines Emerging Technologies: Mobile code (JAVA, JAVAscript), Virtual environments (VRML), Collaborative tools

1996

Internet phones catch the attention of US telecommunication companies who ask the US Congress to ban the technology (which has been around for years)

The controversial US Communications Decency Act (CDA) becomes law in the US in order to prohibit distribution of indecent materials over the Net. A few months later a three-judge panel imposes an injunction against its enforcement. Supreme Court unanimously rules most of it unconstitutional in 1997.

9,272 organizations find themselves unlisted after the InterNIC drops their name service as a result of not having paid their domain name fee 
Various ISPS suffer extended service outages, bringing into question whether they will be able to handle the growing number of users. AOL (19 hours), Netcom (13 hours), AT\&T WorldNet (28 hours email only)

New Yorks' Public Access Networks Corp (PANIX) is shut down after repeated SYN attacks by a cracker using methods outlined in a hacker magazine (2600)

Various US Government sites are hacked into and their content changed, including CIA, Department of Justice, Air Force

MCI upgrades Internet backbone adding 13,000 ports, bringing the effective speed from 155Mbs to 622Mbs.

The Internet Ad Hoc Committee announces plans to add 7 new generic Top Level Domains (gTLD): .firm, .store, .web, .arts, .rec, .info, registrars worldwide.

A malicious cancelbot is released on USENET wiping out more than 25, 000 messages.

The WWW browser war, fought primarily between Netscape and Microsoft, has rushed in a new age in software development, whereby new releases are made quarterly with the help of Internet users eager to test upcoming (beta) versions.

Restrictions on Internet use around the world:

- China: requires users and ISPs to register with the police

- Germany: cuts off access to some newsgroups carried on Compuserve

- Saudi Arabia: confines Internet access to universities and hospitals

- Singapore: requires political and religious content providers to register with the state

- New Zealand: classifies computer disks as "publications" that can be censored and seized

- source: Human Rights Watch

vBNS additions: Baylor College of Medicine, Georgia Tech, Iowa State Univ, Ohio State Univ, Old Dominion Univ, Univ of CA, Univ of CO, Univ of Chicago, Univ of IL, Univ of MN, Univ of PA, Univ of TX, Rice Univ

CERT advisories: 27 , reports: 2573 
Country domains registered: Qatar (QA), Vientiane (LA), Djibouti (DJ), Niger (NE), Central African Republic (CF), Mauretania (MF), Oman (OM), Norfolk Island (NF), Tuvalu (TV), French Polynesia (PF), Syria (SY), Aruba (AW), Cambodia (KH), French Guiana (GF), Eritrea $(\mathrm{ER})$, Cape Verde (CV), Burundi (BI), Benin (BJ) Bosnia-Hercegovina $(B A)$, Andorra (AD), Guadeloupe (GP), Guernsey (GG), Isle of Man (IM), Jersey (JE), Lao (LA), Maldives (MV), Marshall Islands (MH), Mauritania (MR), Northern Mariana Islands (MP), Rwanda (RW), Togo $(\mathrm{TG})$, Yemen (YE), Zaire (ZR)

Technologies of the Year: Search engines, JAVA, Internet Phone Emerging Technologies: Virtual environments (VRML), Collaborative tools, Internet appliance (Network Computer)

1997

2000th RFC: "Internet Official Protocol Standards"

71,618 mailing lists registered at Liszt, a mailing list directory

The American Registry for Internet Numbers (ARIN) is established to handle administration and registration of IP numbers to the geographical areas currently handled by Network Solutions (InterNIC), starting March 1998.

Early in the morning of 17 July, human error at Network Solutions causes the DNS table for. com and . net domains to become corrupted, making millions of systems unreachable.

Longest hostname registered with InterNIC:

CHALLENGER . MED . SYNAP SE . UAH . UALBERTA. CA

101,803 Name Servers in whois database

CERT advisories thus far: 23

Country domains registered: Falkland Islands (FK), East Timor (TP), Congo (CG), Christmas Island (CX), Gambia (GM), Guinea-Bissau (GW), Haiti (HT), Iraq (IQ), Lybia (LY), Malawi (MW), Martinique (MQ), Montserrat (MS), Myanmar (MM), French Reunion Island (RE), Seychelles (SC), Sierra Leone (SL), Sudan (SD), Turkmenistan (TM), Turks and Caicos Islands (TC), British Virgin Islands (VG)

Technologies of the Year: Push, Multicasting Emerging Technologies: Push, Streaming Media [:twc:] 
Growth

Internet growth:

\begin{tabular}{|c|c|c|c|c|c|}
\hline Date & Hosts & Date & Hosts & Networks & Domains \\
\hline----- & --------- & ----- & --------- & -------- & ------ \\
\hline 1969 & 4 & $07 / 89$ & 130,000 & 650 & 3,900 \\
\hline $04 / 71$ & 23 & $10 / 89$ & 159,000 & 837 & \\
\hline $06 / 74$ & 62 & $10 / 90$ & 313,000 & 2,063 & 9,300 \\
\hline $03 / 77$ & 111 & $01 / 91$ & 376,000 & 2,338 & \\
\hline $08 / 81$ & 213 & $07 / 91$ & 535,000 & 3,086 & 16,000 \\
\hline $05 / 82$ & 235 & $10 / 91$ & 617,000 & 3,556 & 18,000 \\
\hline $08 / 83$ & 562 & $01 / 92$ & 727,000 & 4,526 & \\
\hline $10 / 84$ & 1,024 & $04 / 92$ & 890,000 & 5,291 & 20,000 \\
\hline $10 / 85$ & 1,961 & $07 / 92$ & 992,000 & 6,569 & 16,300 \\
\hline $02 / 86$ & 2,308 & $10 / 92$ & $1,136,000$ & 7,505 & 18,100 \\
\hline $11 / 86$ & 5,089 & $01 / 93$ & $1,313,000$ & 8,258 & 21,000 \\
\hline $12 / 87$ & 28,174 & $04 / 93$ & $1,486,000$ & 9,722 & 22,000 \\
\hline $07 / 88$ & 33,000 & $07 / 93$ & $1,776,000$ & 13,767 & 26,000 \\
\hline $10 / 88$ & 56,000 & $10 / 93$ & $2,056,000$ & 16,533 & 28,000 \\
\hline \multirow[t]{9}{*}{$01 / 89$} & 80,000 & $01 / 94$ & $2,217,000$ & 20,539 & 30,000 \\
\hline & & $07 / 94$ & $3,212,000$ & 25,210 & 46,000 \\
\hline & & $10 / 94$ & $3,864,000$ & 37,022 & 56,000 \\
\hline & & $01 / 95$ & $4,852,000$ & 39,410 & 71,000 \\
\hline & & $07 / 95$ & $6,642,000$ & 61,538 & 120,000 \\
\hline & & $01 / 96$ & $9,472,000$ & 93,671 & 240,000 \\
\hline & & $07 / 96$ & $12,881,000$ & 134,365 & 488,000 \\
\hline & & $01 / 97$ & $16,146,000$ & & 828,000 \\
\hline & & $07 / 97$ & $19,540,000$ & & $1,301,000$ \\
\hline
\end{tabular}

Worldwide Networks Growth: (I) nternet (B) ITNET (U) UCP (F) IDONET (O) SI

\begin{tabular}{lrrrrr} 
& \multicolumn{5}{c}{ \# Countries } \\
\cline { 2 - 5 } Date & I & B & U & \multicolumn{1}{c}{ F } & O \\
----- & --- & --- & --- & --- & --- \\
$09 / 91$ & 31 & 47 & 79 & 49 & \\
$12 / 91$ & 33 & 46 & 78 & 53 & \\
$02 / 92$ & 38 & 46 & 92 & 63 & \\
$04 / 92$ & 40 & 47 & 90 & 66 & 25 \\
$08 / 92$ & 49 & 46 & 89 & 67 & 26 \\
$01 / 93$ & 50 & 50 & 101 & 72 & 31 \\
$04 / 93$ & 56 & 51 & 107 & 79 & 31 \\
$08 / 93$ & 59 & 51 & 117 & 84 & 31
\end{tabular}

\begin{tabular}{lrrrrr} 
& \multicolumn{5}{c}{ \# Countries } \\
\cline { 2 - 6 } Date & I & B & U & \multicolumn{1}{c}{ F } & O \\
----- & --- & --- & --- & --- & --- \\
$02 / 94$ & 62 & 51 & 125 & 88 & 31 \\
$07 / 94$ & 75 & 52 & 129 & 89 & 31 \\
$11 / 94$ & 81 & 51 & 133 & 95 & -- \\
$02 / 95$ & 86 & 48 & 141 & 98 & -- \\
$06 / 95$ & 96 & 47 & 144 & 99 & -- \\
$06 / 96$ & 134 & -- & 146 & 108 & -- \\
$07 / 97$ & 171 & -- & 147 & 108 & --
\end{tabular}


WWW Growth:

\begin{tabular}{lr|lr|rr} 
Date & \multicolumn{1}{c|}{ Sites } & Date & Sites & Date & \multicolumn{1}{l}{ Sites } \\
---- & -------- & + & ---- & -------- & + \\
$06 / 93$ & 130 & $08 / 96$ & 342,081 & $04 / 97$ & $1,002,612$ \\
$12 / 93$ & 623 & $09 / 96$ & 397,281 & $05 / 97$ & $1,044,163$ \\
$06 / 94$ & 2,738 & $10 / 96$ & 462,047 & $06 / 97$ & $1,117,255$ \\
$12 / 94$ & 10,022 & $11 / 96$ & 525,906 & $07 / 97$ & $1,203,096$ \\
$06 / 95$ & 23,500 & $12 / 96$ & 603,367 & $08 / 97$ & $1,269,800$ \\
$01 / 96$ & 100,000 & $01 / 97$ & 646,162 & $09 / 97$ & $1,364,714$ \\
$06 / 96$ & 252,000 & $02 / 97$ & 739,688 & & \\
$07 / 96$ & 299,403 & $03 / 97$ & 883,149 & &
\end{tabular}

USENET Growth:

\begin{tabular}{|c|c|c|c|c|c|c|c|c|c|}
\hline Date & Sites & $\sim \mathrm{MB}$ & Posts & Groups & Date & Sites & $\sim \mathrm{MB}$ & Posts & Groups \\
\hline--- & ----- & --- & ------ & ------ & ---- & ------- & --- & ------ & ------ \\
\hline 1979 & 3 & & 2 & 3 & 1987 & 5,200 & 2 & 957 & 259 \\
\hline 1980 & 15 & & 10 & & 1988 & 7,800 & 4 & 1933 & 381 \\
\hline 1981 & 150 & 0.05 & 20 & & 1990 & 33,000 & 10 & 4,500 & 1,300 \\
\hline 1982 & 400 & & 35 & & 1991 & 40,000 & 25 & 10,000 & 1,851 \\
\hline 1983 & 600 & & 120 & & 1992 & 63,000 & 42 & 17,556 & 4,302 \\
\hline 1984 & 900 & & 225 & & 1993 & 110,000 & 70 & 32,325 & 8,279 \\
\hline 1985 & 1,300 & 1.0 & 375 & & 1994 & 180,000 & 157 & 72,755 & 10,696 \\
\hline 1986 & 2,200 & 2.0 & 946 & 241 & 1995 & 330,000 & 586 & 131,614 & \\
\hline
\end{tabular}

3. Sources

Hobbes' Internet Timeline was compiled from a number of sources, with some of the stand-outs being:

Cerf, Vinton (as told to Bernard Aboba). "How the Internet Came to Be." This article appears in "The Online User's Encyclopedia," by Bernard Aboba. Addison-Wesley, 1993.

Hardy, Henry. "The History of the Net." Master's Thesis, School of Communications, Grand Valley State University. http://www.ocean.ic.net/ftp/doc/nethist.html

Hardy, Ian. "The Evolution of ARPANET email." History Thesis, UC Berkeley .

http://server.berkeley.edu/virtual-berkeley/email_history 
Hauben, Ronda and Michael. "The Netizens and the Wonderful World of the Net."

http://www.columbia.edu/ hauben/netbook/

Kulikowski, Stan II. "A Timeline of Network History." (author's email below)

Quarterman, John. "The Matrix: Computer Networks and Conferencing Systems Worldwide." Bedford, MA: Digital Press. 1990

"ARPANET, the Defense Data Network, and Internet". Encyclopedia of Communications, Volume 1. Editors: Fritz Froehlich, Allen Kent. New York: Marcel Dekker, Inc. 1991

Internet growth summary compiled from:

- zone program reports maintained by Mark Lottor at: ftp: //ftp.nw.com/pub/zone/

- connectivity table maintained by Larry Landweber at: ftp://ftp.cs.wisc.edu/connectivity_table/

WWW growth summary compiled from:

- Web growth summary page by Matthew Gray of MIT: http://www.mit.edu/people/mkgray/net/web-growth-summary.html

- Netcraft at http://www.netcraft.com/survey/

USENET growth summary compiled from Quarterman and Hauben sources above, and news.lists postings. Lots of historical USENET postings also provided by Tom Fitzgerald (fitz@wang.com).

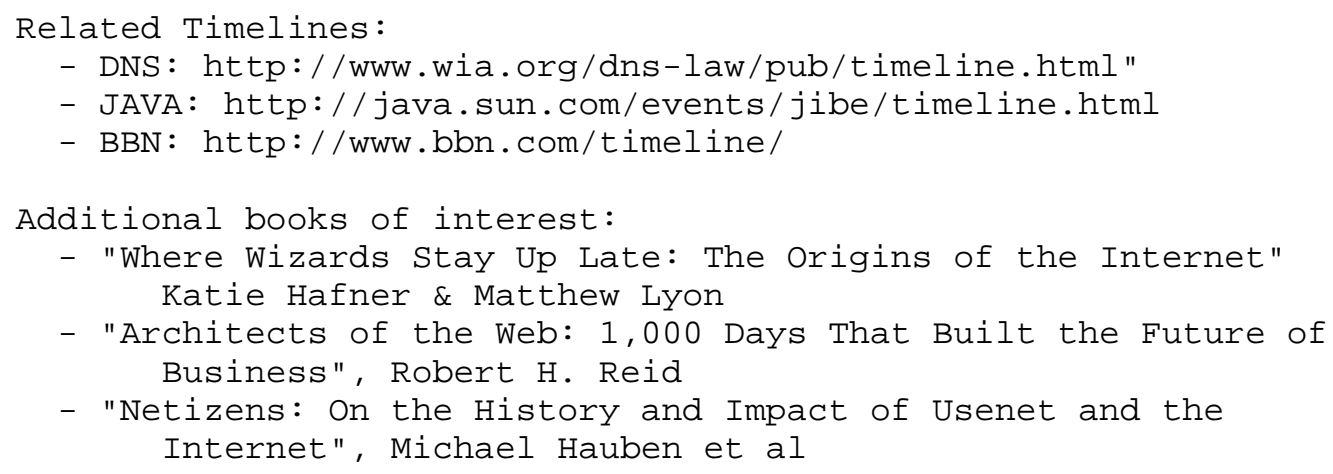




\section{Acknowledgements}

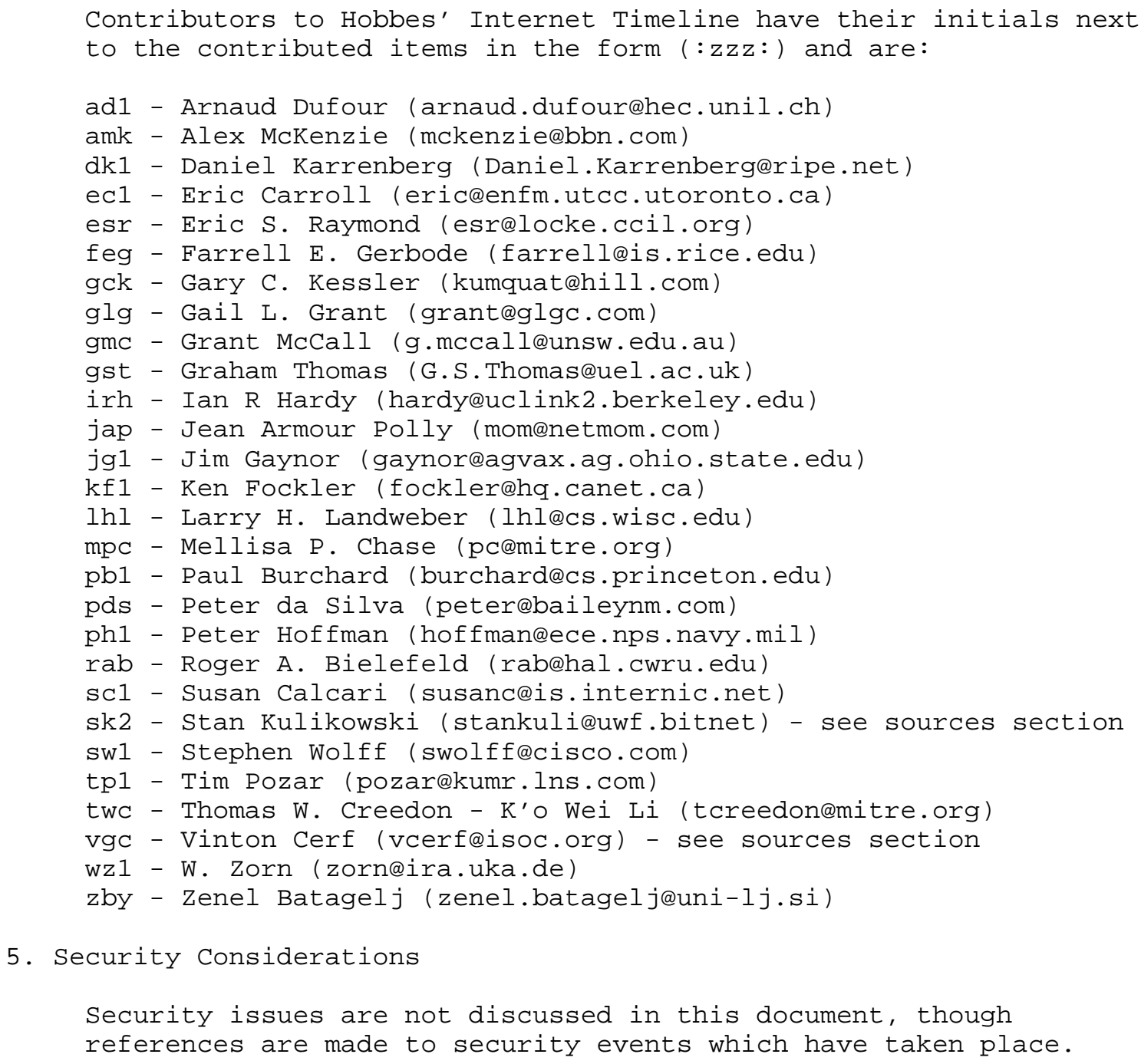


6. Author's Address

Robert $\mathrm{H}$. Zakon

Internet Evangelist

The MITRE Corporation

1820 Dolley Madison Blvd

McLean, Virginia, USA 22102

Phone: (703) 883-7790

EMail: zakondinfo.isoc.org

7. Disclaimer

The views expressed in this document are the author's and are not intended to represent in any way The MITRE Corporation or its opinions on this subject matter. 
8. Full Copyright statement

Copyright (C) Robert H. Zakon and The Internet Society (1997). All Rights Reserved.

This document and translations of it may be copied and furnished to others, and derivative works that comment on or otherwise explain it or assist in its implmentation may be prepared, copied, published and distributed, in whole or in part, without restriction of any kind, provided that the above copyright notice and this paragraph are included on all such copies and derivative works. However, this document itself may not be modified in any way, such as by removing the copyright notice or references to the Internet society or other Internet organizations, except as needed for the purpose of developing Internet standards in which case the procedures for copyrights defined in the Internet Standards process must be followed, or as required to translate it into languages other than English.

The limited permissions granted above are perpetual and will not be revoked by the Internet society or its successors or assigns.

This document and the information contained herein is provided on an "AS IS" basis and THE INTERNET SOCIETY AND THE INTERNET ENGINEERING TASK FORCE DISCLAIMS ALL WARRANTIES, EXPRESS OR IMPLIED, INCLUDING BUT NOT LIMITED TO ANY WARRANTY THAT THE USE OF THE INFORMATION HEREIN WILL NOT INFRINGE ANY RIGHTS OR ANY IMPLIED WARRANTIES OF MERCHANTABILITY OR FITNESS FOR A PARTICULAR PURPOSE. 